Los cuerpos como espacios de inscripción del poder: la experiencia de la prisión política en la Argentina durante los años sesenta y setenta

\title{
Los cuerpos como espacios de inscripción del poder: la experiencia de la prisión política en la Argentina durante los años sesenta y setenta
}

\section{The bodies as spaces of inscription of power: the experience of the political prison in Argentina during the 60's and 70's}

\author{
Débora D'Antonio \\ Instituto de Investigaciones en Estudios de Género \\ Facultad de Filosofía y Letras, Universidad de Buenos Aires, \\ Consejo Nacional de Investigaciones Científicas y Técnicas (Argentina) \\ deboradantonio@hotmail.com
}

\begin{abstract}
Resumen
En este artículo me propongo demostrar, en primera instancia, que el proceso de puesta en valor del sistema penitenciario de mediados de los años sesenta, lo que las elites gobernantes llamaron "modernización carcelaria", fue compatible con un uso amplificado de la violencia. Es en tal sentido que la administración del castigo de un número creciente de personas acusadas de cometer delitos políticos formó parte de un sistema represivo cada vez más centralizado. La "modernización carcelaria", no solo no trajo aparejado el decrecimiento de la violencia del Estado, sino que, por el contrario, se profundizó al calor del ascenso del conflicto social. Específicamente, la trama de la ortopedia carcelaria en los años de la última dictadura militar estuvo obsesivamente unida a la idea de reformar a los "subversivos" con técnicas de disciplinamiento rigurosos, reglamentos requisitorios y restrictivos, y clasificaciones penitenciarias. En tal sentido, y en segunda instancia, me propongo demostrar que los "tratamientos de recuperación" incluyeron a la dimensión de género como un elemento constituyente de la tecnología disciplinadora. La penalización de la condición de género y de la sexualidad fue utilizada como una estrategia para ultrajar a prisioneros y prisioneras y para colocarlos en posición de víctimas y no de adversarios políticos. Así, los cuerpos se transformaron en espacios donde se inscribieron y dirimieron lógicas de poder y se convirtieron, a la vez, en un área de disputa en torno a estas atribuciones. El cuerpo de las mujeres y de los varones prisioneros políticos se delimitó como un territorio ostensible de cuya apropiación dependía el ejercicio del poder, y si bien la destrucción ideológica fue el objetivo prioritario del régimen ésta se consumó de hecho por medio del sistema sexo-género.
\end{abstract}

\section{Palabras Clave}

Esta obra está sujeta a la Licencia Reconocimiento-NoComercial-CompartirIgual 4.0 Internacional de Creative Commons. http://creativecommons.org/licenses/by-nc-sa/4.0/ 


\title{
Débora D'Antonio
}

modernización carcelaria; violencia; penalización; género; sexualidad; cuerpos

\begin{abstract}
In this article my proposal is to, in first instance, demonstrate that the enhancing process of the penitentiary system of the mid 70's, what the governing elites called "modernization of prison", was compatible with an amplified utilization of violence. Hence, the penalty's administration of an increasing number of people being accused of committing political offences took part of a repressive system, each time more centralized. The "modernization of prison", not only did not bring the decrease of state violence along, but also, in the contrary, brought a deepening in the heat of the rising social conflict. Specifically, the weft of the prison discipline, during the last military dictatorship, was obsessively tied to the idea of reforming the "subversives" with rigorous control techniques, requisite and restrictive regulations and penitentiary classifications. Along these lines and, in second instance, my proposal is to demonstrate that the "recovery treatments" included the gender dimension as a constituent element of disciplinary technology. The criminalization of gender and sexuality was used as a strategy to outrage male and female prisoners and to place them in the position of victims and not as political adversaries. Therefore, the bodies were transformed into spaces where power logics were written and settled and, at the same time, became an area of dispute over these attributions. The body of women and male political prisoners was delimited as an ostensible territory of which appropriation depended of the exercise of power, and despite the fact that the main objective of the regime was the ideological destruction, it was, in fact, consumed through the sex-gender system.
\end{abstract}

\section{Keywords}

modernization of prison; violence; penalty; gender; sexuality; bodies

\section{Introducción}

Todavía con la inercia de la administración humanista de Roberto Pettinato, Director Nacional de Institutos Penales, en enero de 1958 durante el gobierno de facto de Pedro Ignacio Aramburu, fue aprobada la primera ley Penitenciaria Nacional. La misma tuvo por finalidad, y en el marco de la creación de distintos territorios provinciales, unificar legalmente al régimen carcelario y limitar o erradicar las irregularidades existentes. ${ }^{1}$ En tal sentido, fijó, por ejemplo, que a los condenados no se las podría denominar más como reos sino como internos, y que no se los podría emplazar más por medio de números o apodos sino a través de sus nombres y apellidos. Reglamentó, asimismo, que la vestimenta no debía ser humillante, correspondiéndole a la misma un aseo regular, y orientó el suministro de la alimentación con un criterio nutricional impartido por el personal del servicio de salud del servicio. La nueva ley expresó prohibiciones explícitas en torno al uso de esposas, ganchos, grilletes, chalecos o camisas de fuerza, a excepción de que existiesen tentativas de evasión o uso de armas de blancas o de fuego por parte de la población carcelaria. Coherente con estos anhelos globales, en su cuarto capítulo,

\footnotetext{
${ }^{1}$ El decreto ley $\mathrm{N}^{\circ} 412$ del 14 de enero de 1958 fue ratificado por el parlamento por medio de la sanción de la Ley Penitenciaria Nacional N. o 14.467, que se convirtió en una normativa complementaria del Código Penal.
} 


\section{Los cuerpos como espacios de inscripción del poder: la experiencia de la prisión política en la Argentina durante los años sesenta y setenta}

estableció que el trabajo penitenciario, siendo obligatorio, debía ser utilizado únicamente como medio de tratamiento ajustado a la aptitud física y mental de los internos, y no como simple castigo añadido. Existía de tal modo en la nueva normativa, la convicción de que la persona detenida podía regenerarse por medio de labores manuales en los talleres carcelarios y no a través del uso de la violencia física. La ley ponía coto a "toda sanción cruel e inhumana, infamante o degradante, los aislamientos en celdas oscuras o desmanteladas, la reducción de alimentos y todo otro método que pudiera alterar la salud física o mental del interno" (Marcó del Pont, 1982: 142).

Tan solo una década más tarde, sin embargo, cuando la administración del gobierno militar de Juan Carlos Onganía definió que era necesario poner en valor al sistema penitenciario por el significativo incremento del número de personas apresadas por razones políticas, lejos de apostar a "un encierro digno", profundizó las transformaciones por medio de la utilización estructural de métodos coercitivos y violentos. De modo que el proceso de adecuación de las cárceles guardó relación directa con la estrategia represiva integral del Estado que por entonces era congruente con el ideario antisubversivo dominante durante la Guerra Fría. Si bien las instituciones penitenciarias desde sus orígenes habían incluido dentro de su agenda de tareas la represión a las actividades políticas calificadas como opositoras, desde mediados de los años sesenta y, en particular en el último tramo de la década, la misma se tornó un motor central. Esto fue así tanto por el papel que le asignó el Poder Ejecutivo a las espacios de detención, ante el ascenso del conflicto social, como por la colaboración directa que trabaron las Fuerzas Penitenciarias con las Fuerzas Armadas, y que finalmente se consumó en la política de subsunción de la primera a la segunda a través de la figura del control operacional. ${ }^{2}$ Sin embargo, la traducción institucional de la Doctrina de Seguridad Nacional, que colocaba en el centro de la persecución al delito político y al "enemigo interno", no se reflejó en la ley penitenciaria nacional, que, por el contrario, seguía ofreciendo una cobertura formal a las mecanismos represivos mientras sus presupuestos eran vulnerados.

En este nuevo contexto ya no se dispuso de un espacio para la rehabilitación y reforma de los sujetos caracterizados como "subversivos", tal como lo había practicado en otros períodos históricos el sistema penitenciario con el delincuente común. Sino por el contrario, progresivamente, y con un pico durante la dictadura militar que tuvo inicio con el golpe de marzo del año 1976, el sistema aplicó procedimientos y reglamentos enmarcados en una "lógica de guerra interna" cada vez más rigurosos. De modo tal que, la perspectiva reformista que la ley

\footnotetext{
${ }^{2}$ Según la ley N. o 19.594, donde las Fuerzas Armadas se comprometían directamente en la lucha antisubversiva por control operacional debía entenderse "la facultad de los Comandantes en Jefe de las respectivas Fuerzas Armadas, de imponer misiones a organismos con responsabilidad de brindar alojamiento de condenados, procesados y detenidos por los hechos de referencia, y al personal de los mismos, como así también ejercer el control del cumplimiento de las citadas misiones". Ver Boletín Público del Servicio Penitenciario Federal, N. o 830, del 02/06/72.
} 


\section{Débora D'Antonio}

penitenciaria había intentado implantar, se mostró en abierta contradicción con un Estado que redefinía sus órganos de vigilancia, espionaje y control a fin de tornar más eficaz la persecución a los distintos sectores sociales y políticos que se encontraban ampliamente movilizados. No se trata, sin embargo, de presentar un pasado idílico penitenciario que, antes del radical ascenso de la lucha entre las clases de los años sesenta y setenta en Argentina, cumplía con sus postulados reformadores. Es fundamental señalar, no obstante, que antes de que las instituciones de castigo se acoplaran abiertamente en favor de la lucha antisubversiva, aunque hubiesen existido personas apresadas por razones políticas, el eje de las mismas pasaba por el control social del crimen y no por el del delito político. Por tal motivo, la prisión durante estas décadas no puede ser concebida como una anomalía respecto del desarrollo histórico "normal" de la historia argentina, sino por el contrario, debe ser considerada en estrecha relación con otros aparatos de Estado que procesaban los conflictos sociales y políticos de un modo cada vez más represivo. En octubre de 1972, durante el gobierno dictatorial de Alejandro Lanusse, fue aprobado, por ejemplo, el decreto ley ‥ $\stackrel{0}{19.863}$, conocido como "Reglamento de Detenidos de Máxima Peligrosidad". Este involucraba tanto a personas detenidas a disposición del Poder Ejecutivo Nacional -encarceladas por decisión presidencial sin proceso judicial ni condena alguna-, como a condenados por la justicia federal. ${ }^{3}$ El mismo se proponía elaborar un régimen único para quienes hubiesen sido apresados por razones políticas, diferente del que se aplicaba a los presos que habían cometidos delitos comunes. El decreto introdujo, además, en su fundamentación la idea de las "personas peligrosas": una calificación que no exigía haber incurrido en la concreción efectiva y material del delito sino tan solo en portar la intencionalidad de cometerlo (Foro de Buenos Aires por la Vigencia de los Derechos Humanos, 1973: 93-94). Este, por otro lado, debía ser aplicado fundamentalmente en las instituciones penitenciarias caracterizadas como de máxima seguridad y abocadas al tratamiento de prisioneros políticos. Este fue el caso, por ejemplo, del buque Granadero ${ }^{4}$, del penal de Resistencia en el Chaco, del de Rawson en la provincia de Chubut y del de Villa Devoto en la capital del país. En sus considerandos también se establecían pabellones enteros divididos por sexo con encierros de 24 horas al día y en celdas individuales. Se imponía el uniforme de color naranja, se restringían las lecturas de diarios, revistas y libros, se impedía la escucha de canales de radiodifusión, y junto a ello, también la visita de los abogados defensores. A la vez sus considerandos dejaban un margen discrecional para la aplicación de tormentos y castigos arbitrarios. El "Reglamento de Detenidos de Máxima Peligrosidad" fue el primer intento sistemático y centralizado que apuntó a desarticular todo intento de ejercicio de oposición por medio de la destrucción física

\footnotetext{
${ }^{3}$ Ley N. o 19.863 ver en Boletín Oficial del 13/10/72.

${ }^{4}$ El buque Granadero era un carguero en desuso de la Empresa Líneas Marítimas Argentinas (ELMA), que estaba anclado en una dársena del puerto de Buenos Aires. Dependía de la Prefectura Naval Argentina y fue entregado al Servicio Penitenciario Federal como un sitio de detención de personas prisioneras políticas (Ver este tema en Eidelman, 2010).
} 


\section{Los cuerpos como espacios de inscripción del poder: la experiencia de la prisión política en la Argentina durante los años sesenta y setenta}

y psíquica de los prisioneros (Bergalli, 1972; Baigún, 1973b). Entre los años 1974 y 1976, primero durante el gobierno de Juan Domingo Perón, y luego durante el de María Estela Martínez de Perón, cuando todavía se conservaba algún viso de legalidad y en seguida de la liberación masiva de presos y presas de mayo de 1973, tuvo lugar un nuevo y revelador deterioro de las condiciones de vida penitenciarias. En primera instancia porque se habían profundizado los esfuerzos de especialización del sistema penitenciario a través de la existencia de unidades carcelarias donde se reforzaban las condiciones de aislamiento e inmovilización. Y, en segundo lugar, porque toda la arquitectura jurídica del Estado apuntó a engrosar la población de las prisiones políticas, por entonces espacio exclusivo de reclusión ante la amplificada persecución estatal. Ya durante los años de la última dictadura militar (1976-1983), donde tuvo lugar el novedoso dispositivo de encierro plasmado en la figura de los centros clandestinos detención, las cárceles volvieron a sufrir cambios virulentos al convertirse en la cara visible de una represión que se llevaba a cabo fuertemente de manera oculta.

En este artículo me propongo, en primera instancia, mostrar que el proceso de puesta en valor del sistema penitenciario de mediados de los años sesenta, lo que las elites gobernantes llamaron "modernización carcelaria", fue compatible con un uso amplificado de la violencia. Es en tal sentido que la administración del castigo de un número creciente de personas acusadas de cometer delitos políticos formó parte del sistema represivo cada vez más centralizado. La "modernización carcelaria", no solo no trajo aparejado el decrecimiento de la violencia del Estado, sino que, por el contrario, es posible afirmar que la misma se profundizó al calor del ascenso del conflicto social. Específicamente, la trama de la ortopedia carcelaria en los años de la última dictadura militar estuvo obsesivamente unida a la idea de reformar a los "subversivos" con técnicas de disciplinamiento rigurosos, reglamentos requisitorios y restrictivos, así como también de clasificaciones penitenciarias que tenía por finalidad dividir internamente a la población penitenciaria. En segunda instancia, me propongo mostrar que los "tratamientos de recuperación" incluyeron a la dimensión de género como un elemento constituyente de la tecnología disciplinadora. La penalización de la condición de género y de la sexualidad fue utilizada como una estrategia para ultrajar a los prisioneros y las prisioneras, y colocarlos en posición de víctimas y no de adversarios políticos. Así, sus cuerpos se transformaron en espacios donde se inscribieron y dirimieron lógicas de poder y se convirtieron, a la vez, en un área de disputa en torno a estas atribuciones. El cuerpo de las mujeres y de los varones prisioneros políticos se delimitó como un territorio ostensible de cuya apropiación dependía el ejercicio del poder. Y si bien la destrucción ideológica fue el objetivo prioritario del régimen penitenciario ésta se consumó de hecho por medio del sistema sexo-género.

Mientras en la primera parte analizo las formas en que la violencia tomó forma en el cuerpo de las prisioneras políticas a partir del examen de las fichas médicas elaboradas por el personal penitenciario del penal de Villa Devoto entre 1976 y 


\section{Débora D'Antonio}

19835; en la segunda, por medio de la lectura de la causa judicial No. 500 sobre apremios ilegales practicados en el penal de Rawson en el mismo período histórico, exploro la estrategia represiva que se aplicó sobre los varones presos políticos ${ }^{6}$.

\section{Devoto campo de batalla sexual}

Como ya se ha señalado, en el período que se aplicó en las cárceles la Doctrina de Seguridad Nacional, la violencia política se enlazó de modo profundo con la violencia de género y sexual. En tal sentido, en Villa Devoto, por ejemplo, un penal federal donde fueron centralizadas las presas políticas, no primó un tratamiento de resocialización como el que habían practicado las monjas de la Congregación del Buen Pastor en su larga administración del castigo femenino. Mientras las religiosas buscaban la refeminización de las prisioneras por medio del ensayo de tareas asociadas con los roles de género tradicionales como la elaboración de manualidades o la confección de prendas, por un lado, y el recogimiento devoto, por otro; la propuesta del sistema penitenciario se centró en diversos mecanismos de disciplinamiento que partían del ultraje a la condición de género. Esto se expresó, por ejemplo, en el tratamiento que el penal ofreció a las madres presas políticas, al desentenderse de implementar cualquier estrategia institucional mínima para garantizarles los derechos a ellas y a sus pequeños hijos e hijas. Si en una primera instancia el Servicio Penitenciario Federal, dependiente del Poder Ejecutivo nacional, las reunió en el pabellón original de contraventoras, donde hasta junio de 1976 habían nacido diecisiete criaturas, en un gesto inicial que pareció de preservación, rápidamente las condiciones de higiene, de alimentación y, en general, de salubridad se mostraron colosalmente deficitarias. Por lo que los menores solían enfermarse continuamente por no contar sus madres con agua caliente, mantas de abrigo o colchones en buen estado, y porque los vidrios rotos no se reparaban ni siquiera durante el crudo invierno porteño. Como la atención médica era, además, precaria o inexistente, en los primeros meses después del golpe de Estado de marzo de 1976, se desataron epidemias de gripe y hepatitis. Por medio de políticas sanitarias y habitacionales desubjetivantes se ejercía en el "pabellón de las madres"

\footnotetext{
${ }^{5}$ Secretaria de Derechos Humanos (1977-1981). Historias Clínicas del Hospital Penitenciario de Devoto. Serie SDH-S24. Fondo Secretaría de Derechos Humanos. Archivo Nacional de la Memoria, Argentina.

${ }^{6}$ La causa $\mathrm{N}^{\circ}$ 500/107/80 lleva por nombre "Sobre apremios y torturas en la Unidad № 6 de la localidad de Rawson" y fue agregada al expediente "Steding Jorge Osvaldo y Govi Ramon Miguel, infracción artículo 144 bis y 142 del CP". En ella se relatan a través de 260 declaraciones, las violaciones a los derechos humanos cometidas en el penal de Rawson durante la última dictadura militar. El expediente fue iniciado en el año 1980, a partir de un recurso de amparo presentado por el entonces preso político, Carlos K. A este expediente inicial se le anexaron otros que lo constituyeron posteriormente en una investigación federal. Lo que permitió reconstruir la estructura represiva de la región, la cadena de mandos del V Cuerpo del Ejército con asiento en Bahía Blanca, así como también la identificación de los centros clandestinos zonales. Fondo Secretaría de Derechos Humanos. Archivo Nacional de la Memoria, Argentina.
} 


\section{Los cuerpos como espacios de inscripción del poder: la experiencia de la prisión política en la Argentina durante los años sesenta y setenta}

una fuerte violencia institucional que alteraba la relación entre las prisioneras y sus hijos e hijas.

Como he advertido en otros trabajos7, las políticas de género desplegadas por el gobierno de la última dictadura se presentaban como operaciones sumamente contradictorias, ya que, por ejemplo, se enaltecía a la mujer y a la maternidad en los discursos públicos, mientras, como es sabido, un cuerpo especializado de médicos, enfermeros, parteras y sacerdotes, bajo órdenes militares, ejercía en los centros clandestinos de detención operaciones de exterminio sobre las militantes parturientas, apropiándose además de sus hijos e hijas recién nacidos. Si bien en las cárceles estas prácticas no alcanzaron tal salvajismo, de igual modo, apuntaron a horadar el vínculo materno-filial. Así, médicos, psicólogos y asistentes sociales tenían por misión infundir entre las prisioneras sentimientos de culpa, mostrando que sus compromisos políticos las habían llevado a abandonar sus descendencias y que, en tal caso, para remediar esa desatención, lo mejor era permitirles a esos hijos e hijas crecer en casas donde se les proporcionasen valores morales auténticos. En ese sentido, cuando no hubo familias a las que se les pudiese entregar a los menores, el servicio penitenciario intentó promover adopciones no consentidas por las madres. Cuestiones que, por cierto, no eran tan diferentes de las practicadas por las Juntas Militares respecto de los menores que eran convertidos en "botines de guerra" en los centros clandestinos de detención. La idea de entregar ilegalmente a muchos de esos bebés a familias afines a los militares y sustituirles su identidad suprimiendo los cuerpos biológicos de sus madres, se sostenía en la presunción de que esas prisioneras eran mujeres amorales, desviadas de la verdadera esencia de su sexo, y que, por lo tanto, eran merecedoras de todo tipo de violencia física y psíquica.

El análisis de las historias clínicas originadas en la división asistencia médica del penal de Villa Devoto permite comprender en mejor grado cómo afectó a los cuerpos femeninos la represión estatal, y comprender también las formas con las que se intentó ahondar en la desubjetivación de las prisioneras políticas.

En esta documentación se registraron las fechas en las que las prisioneras ingresaban al penal y dónde habían sido detenidas, revelando que el traslado masivo de mujeres a la cárcel de Villa Devoto tuvo lugar entre los últimos meses de 1975 y los primeros de 1976. Asimismo, a partir de los testimonios ofrecidos por las prisioneras políticas años después en sede judicial o en la de los organismos de derechos humanos, se sabe que los traslados a los penales de máxima de seguridad, como el de Villa Devoto, se llevaron a cabo por medio de aviones "Hércules" del Ejército Argentino. El "Hércules" era una máquina de guerra con un compartimiento de carga libre que permitía adaptar con rapidez el espacio para el traslado de seres humanos, camillas o tropas. Las prisioneras viajaban encadenadas al piso de la aeronave, y tanto en el momento de subir a la misma, como durante el viaje, o luego, una vez que eran movilizadas en los vehículos penitenciarios, fueron golpeadas de

${ }^{7}$ Ver por ejemplo, D’Antonio, 2016. 


\section{Débora D'Antonio}

manera deliberada, aun habiendo, entre ellas, mujeres embarazadas y lisiadas. De hecho, al llegar al penal metropolitano, el personal penitenciario que efectuaba el informe de ingreso, anotaba "burocráticamente" en las fichas, sin indagar profundamente en ninguna razón, las penetrantes lastimaduras y los magullones que portaban las prisioneras en distintas partes de sus cuerpos. En las mismas historias clínicas se consignaba, además, la existencia de desmayos y de severos cuadros de deshidratación provocados por las condiciones de hacinamiento durante los traslados que en su mayoría se efectuaron en un período del año en el que las condiciones climáticas eran sumamente tórridas, entre octubre y marzo. En algunos de esos documentos se detallaba, además, que las prisioneras mostraban hematomas dorsales o de traumatismos costales, por lo que los médicos, frente al intenso dolor referido por las flamantes internas, solicitaban la realización de estudios radiográficos para cerciorarse, por ejemplo, de que no hubiese fracturas. Asimismo, en algunas historias clínicas, curiosamente y, por el contrario, se señalaba que "la ingresante no presenta lesiones de ningún tipo", queriendo los médicos deslindarse de responsabilidades futuras. ${ }^{8}$

Los médicos penitenciarios para confeccionar estos documentos realizaban una primera entrevista en la que obtenían información que centralmente remitía a épocas pretéritas de la historia biológica de las prisioneras. De modo que con las preguntas se profundizaba en las posibles enfermedades que hubiesen dejado secuelas en los cuerpos de las prisioneras, en los antecedentes de la primera infancia o en las operaciones que se les hubiesen practicado. En las historias clínicas se atesoraban también las causas que motivaron a las presas a acudir a la consulta clínica, las conclusiones diagnósticas de los médicos, el tratamiento propuesto y las razones de la remisión cuando estas existieron.

En cada una de las historias clínicas se anotaban obsesivamente datos sobre el peso de las prisioneras haciendo ostensible a simple vista las importantes variaciones que cada una de ellas sufría mes a mes, así como la pérdida sustantiva que tuvieron en la masa corporal, sobre todo en los dos primeros años después del golpe. Si el peso promedio que ronda a las mujeres en edad fértil es de entre 50 y 60 kilogramos; las historias clínicas muestran que, en su mayoría, las prisioneras políticas ingresaron al penal metropolitano con un peso muy por debajo del que deberían contar según su edad biológica, producto de las detenciones ilegales, la subalimentación y los fuertes maltratos físicos previos de cárceles provinciales o de sitios temporarios de detención clandestina. Hay que señalar, además que en la misma documentación u en otra ${ }^{9}$, se reponen los años de vida que tenían estas

\footnotetext{
${ }^{8}$ Ver Historia clínica N. ${ }^{\circ}$ 0536, Archivo Nacional de la Memoria. Vale señalar que muchas personas que caían presas por esos años pasaban por violentos interrogatorios y torturas, de hecho, en los informes que realizaban los médicos forenses al ingresar los internos a los penales se asentaba que muchos llegaban con traumatismos múltiples, golpes en las zonas torácicas y quemaduras en los órganos genitales.

${ }^{9}$ En oportunidades junto a las historias clínicas se halló otro tipo de información como, por ejemplo, fichas de traslado, fichas dactilares o de detención. Estos documentos revelan la nacionalidad, la edad, la procedencia, los orígenes sociales familiares, también la conducta que tuvieron en otros
} 


\section{Los cuerpos como espacios de inscripción del poder: la experiencia de la prisión política en la Argentina durante los años sesenta y setenta}

mujeres al momento de su ingreso a Devoto, evidenciando, que, si bien muchas de ellas eran púberes, y otras decanas, el promedio de edad de las prisioneras políticas no superaba el de los 25 años. De modo que, sabiendo que el período de fertilidad femenina se sitúa entre la pubertad y la menopausia, fenómeno que sucede entre los 15 y los 50 años, aproximadamente, es posible asegurar que el encierro afectó en estas mujeres tanto la etapa de mayor fecundidad como la de mayor actividad sexual. Muchas prisioneras padecían fuertes alteraciones menstruales, por ejemplo, tanto por las variaciones en el peso como por el estrés provocado por el encierro. A veces directamente se les producía el retiro del sangrado menstrual, cuestión que en términos técnicos es llamado amenorrea, algo que sucedía para algunas de manera definitiva, y para otras, de forma temporaria. En cualquier caso, en términos del funcionamiento de la subjetividad y del inconsciente, los cuerpos se defendían de las condiciones de dominación encierro y de las consecuencias de cualquier tipo de vejamen o humillación sexual.

En las fichas médicas se puede ver, también, una multiplicidad de patologías que aluden tanto a padecimientos físicos como a psicológicos de estas mujeres. Se repiten en estos documentos, insistentemente, por ejemplo, dolencias provocadas por una alimentación pobre en fibras y en líquidos que potenciaban cuadros crónicos de estreñimiento. Otras historias registran, por su parte, dolores por cólicos gastrointestinales. También se aprecia en las fichas médicas que a muchas prisioneras se les van detectando a lo largo de los muchos años de encierro distintas displasias o nódulos mamarios que posteriormente se terminarían transformando en tumores malignos. Algunas internas manifiestan a los médicos diversos sufrimientos provocados por la inmovilidad que se les impone en las celdas diminutas en las que habitaban. Así se narran edemas en las manos y en las piernas, dolores agudos en la zona de inervación del ciático o lumbalgias o neuritis producidas por la inflamación de uno o más tendones primordialmente por la

\footnotetext{
penales (si hubiese habido detenciones previas), y a veces, hasta la "causa" que daba origen al encierro. En tal sentido sabemos que los lugares de procedencia fueron mayoritariamente de los centros urbanos más importantes del país como Buenos Aires, Rosario y Córdoba, aunque en menor grado, se ven encuentran referencias de mujeres que provenían de distintas franjas rurales de Tucumán, Salta o Chaco e incluso de zonas del interior de las ciudades capitales de estas provincias. También, según se detalla, es posible concluir que la mayoría de las presas políticas eran mujeres alfabetizadas y con un grado de instrucción que podía variar entre la primaria, la secundaria, el terciario o la universidad. Y que incluso, muchas de ellas, portaban la condición de ser estudiantes de escuelas medias al momento de su detención. En estos legajos se registraba además el tipo de inserción laboral arrojando altos porcentajes de mujeres que trabajaban en rubros industriales como el textil, químico o el de alimentación, mientras otras se insertaban en el área de la administración pública, de la educación, de servicios, comercios o finanzas. Finalmente se aprecian en detalle los lugares de reclusión de origen de estas mujeres y se pone en evidencia la existencia de un activismo femenino presente en numerosas provincias del país. Entre las zonas más nombradas se destacan: Villa Gorriti en Jujuy, Villa Las Rosas en Salta, la Alcaidía de Resistencia en Chaco, la Alcaidía de Mujeres de la Jefatura de Policía de Rosario, el Buen Pastor y Jefatura de Policía en Santa Fe, la Unidad N. 1 de Córdoba, la cárcel de Villa Urquiza en Tucumán, la Cárcel de Olmos de la Plata, y otras cárceles como las de Mendoza, Santiago del Estero, La Rioja y Catamarca.
} 


\section{Débora D'Antonio}

carencia en los alimentos de vitaminas y nutrientes. En algunas fichas, se observa que a muchas mujeres se les cae el cabello con frecuencia y modo abundante por el bajo consumo de hierro y de proteínas, y naturalmente, por las brutales condiciones de encierro.

Desfilan, asimismo, en las fichas médicas pólipos uterinos, trastornos vaginales, mastitis en las madres lactantes o en las que dejaron recientemente de dar de mamar, poliquistosis de ovarios, endometrosis y metrorragias que sumado a los estudios de biopsia que se realizaban con frecuencia en útero y ovarios, así como a los estudios de Papanicolau (PAP), completan un cuadro de patologías muy desarrollado y propio del aparato genital femenino, en contraste con la baja cantidad de afecciones que, en promedio, suelen contar las mujeres de la franja de edad que va de los 20 a los 30 años. ${ }^{10}$

Las historias clínicas nos permiten imaginar también cómo tuvieron lugar los distintos focos epidemiológicos producidos por las condiciones de hacinamiento de los pabellones, por lo que en mismo período tuvieron lugar numerosos cuadros de hepatitis, bronquitis agudas, dermatitis por invasión de piojos y chinches en las camas y, con otra jerarquía, pero no por ello sin valor, la micosis interdigital.

Un aspecto sobresaliente de las fichas médicas es el que registra en las internas dificultades de origen psiquiátrico. En este rubro se observan casos de "viscosidad" o de inercia mental,11 de fuerte disminución o desmoronamiento en la memorización, de retorno a posiciones fetales nocturnas, de risas agudas o chillidos histriónicos, así como de otras formas de descompensación psicológica que pueden manifestarse en fuertes cefaleas a crisis depresivas. ${ }^{12}$ En relación a este punto, en el libro de novedades del Hospital Penitenciario Central, se detallan los movimientos del servicio, y entre ellos, el registro del suministro a las internas de psicofármacos. ${ }^{13}$ Se deja en claro que los médicos penitenciarios manejaban a las reclusas, narcotizándolas, por medio de un uso frecuente que tenía como propósito fundamental evitar las autonomías de parte de las prisioneras.

Las historias clínicas exhiben, por un lado, las biografías médicas extensas de las prisioneras políticas, y por otro, la fuerte obsesión institucional por registrarlo todo. En ellas incluso es posible hallar las firmas de los médicos que recepcionaron tales consultas, dejando claro sus responsabilidades en tal actuación. Colisionaba con este registro burocrático el maltrato, la desidia y la perversión que los mismos médicos empleaban contra las prisioneras y su lejanía con los juramentos hipocráticos. ¿Cuál era la respuesta médica, por ejemplo, frente a las dolencias relacionadas con la imposibilidad de realizar ejercicios físicos? "Recomendaban" algo que no era posible de ser efectivizado esto es, por ejemplo, la aplicación de sesiones de masoterapia y de gimnasia. ¿Por qué estas prescripciones clínicas nunca se cumplían? Porque el

\footnotetext{
10 Según información médica, la mayoría de las patologías ginecológicas y mamarias femeninas se presentan a partir de los 40 o 45 años de edad.

${ }^{11}$ Historia Clínica N. ${ }^{\circ} 0402 / 180.981 ;$ N. ${ }^{\circ} 811$ y N. ${ }^{\circ} 178.447$, Archivo Nacional de la Memoria.

${ }^{12}$ Historia Clínica N. ${ }^{\circ} 0178$, Archivo Nacional de la Memoria.

13 Ver los libros de novedades, Archivo Nacional de la Memoria.
} 


\section{Los cuerpos como espacios de inscripción del poder: la experiencia de la prisión política en la Argentina durante los años sesenta y setenta}

penal contaba con reglamentaciones que anulaban la posibilidad de realizar cualquier tipo de ejercicio físico. ${ }^{14}$ Sin embargo, en otras ocasiones, una dolencia menor, como puede ser una torcedura de un tobillo, era utilizada por los mismos penitenciarios para obligar a las presas a que hicieran reposo por largos días, llegando a negarles las visitas de sus seres queridos. Pero también un dolor de muela no era tratado con premura y siempre concluía con la extracción de la pieza dentaria. En términos generales, las fichas médicas nos permiten entender que las prisioneras políticas estuvieron en el penal atravesadas por distintos tipos de violencia física, una mala alimentación, el hacinamiento en pabellones y celdas, y numerosas epidemias. Los síntomas y las enfermedades, por un lado, y los tratamientos y las necesarias intervenciones quirúrgicas por otro, revelan a la vez, el debilitado estado de salud psíquica y física de esta población. En tal sentido, algunas de las ex prisioneras siguen organizando parte de sus relatos en torno a las dolencias que están aún presentes en sus cuerpos como consecuencia de aquellas antiguas prácticas de maltrato. ${ }^{15}$ También las torturas ejercidas en los centros clandestinos de detención, espacios por los que algunas de estas mujeres pasaron antes de su legalización definitiva como presas políticas y que han dejado marcas en sus cuerpos hasta hoy día. Vale destacar, que un conjunto de ex prisioneras sigue presentando síntomas degenerativos como los que se manifiestan en el cáncer. En tal sentido, la escritora y ex presa política Alicia Kozameh se refiere a esos síntomas como marcas "indelebles" que aparecen tanto en la forma de temores, obsesiones y angustias o de trastornos mayores como la depresión o las degeneraciones celulares. Sostiene, además, que los tumores que han sido extirpados o que están controlados siguen siendo razones de ansiedad: "ya sabemos que el estrés prolongado en el tiempo produce cáncer, y se manifiesta años más tarde de la experiencia". ${ }^{16} \mathrm{Si}$ bien no contamos en nuestro país con estudios que prueben de modo efectivo el vínculo entre las vejaciones y la producción de enfermedades orgánicas degenerativas, no es posible soslayar que quienes estuvieron expuestos a la violencia estatal, como en el caso de las ex presas políticas, actualizan permanente aquel antiguo maltrato carcelario, algo que se expresa fuertemente en los testimonios judiciales y en las memorias de estas comunidades. ${ }^{17}$

En síntesis, las fichas médicas nos muestran el modo en que el Estado inscribió en los cuerpos de estas mujeres la tecnología represiva tanto en el plano físico como en

\footnotetext{
${ }^{14}$ Se manifiesta esta prescripción en la Historia Clínica N. ${ }^{\circ}$ 176.792, ANM.

15 También las mujeres uruguayas centraron sus testimonios en torno a tres grandes ejes: la vida en el penal, la relación con sus familiares y fundamentalmente las torturas psíquicas y físicas sufridas Sapriza (2009). Ver también este tema en Merenson (2003).

16 Alicia Kozameh citada en Boccanera (2006): "El testimonio de ex presas políticas de Villa Devoto en el libro Nosotras. Presas políticas" (para la agencia de noticias Télam). Ver http://www.redroom.com/author/alicia-kozameh/bi

17 Un dato interesante es el de la investigación de la médica neuropsiquiatra Paz Rojas, la cual, mediante estudios comparados entre distintas poblaciones víctimas de violencia estatal ha encontrado un patrón de frecuencia de enfermedades degenerativas en familiares de detenidosdesaparecidos en Chile. Rojas (1996).
} 


\section{Débora D'Antonio}

el psíquico, y cómo intentó incidir y alterar la lógica biológica de sus cuerpos en la etapa de mayor fertilidad. Muchos de estos síntomas fueron provocados por las sanciones disciplinarias, el aislamiento, las restricciones del movimiento y en el suministro de los nutrientes necesarios. Una cantidad significativa de estas afecciones fueron de hecho estimuladas por el personal penitenciario con la colaboración de psicólogos, médicos, sociólogos y asistentes sociales, apuntando directa o indirectamente a una política de desubjetivación.

\section{Rawson, piel y hueso}

La perspectiva del "hombre nuevo" propuesta por Ernesto "Che" Guevara y que la militancia revolucionaria tomó en su conjunto como un modelo a seguir, construía una subjetividad política masculina centrada en las nociones de coraje y de heroísmo. A pesar de las diferencias ideológicas que separaban a las fuerzas de seguridad de quienes tenían compromiso militante político y social, las representaciones sobre las masculinidades, y las formas de vivenciarlas se asemejaban mucho entre uno y otro grupo, porque ambas se fundan en el estatuto de la destreza física y de la resistencia corporal. En tal sentido, cuando se perfeccionaron los modos para "quebrar" ideológicamente a los presos políticos en las cárceles se vislumbró la posibilidad de vulnerar su integridad por medio de una estrategia de desmasculinización.

El 30 de mayo de 1980, Carlos Kunkel., abogado y preso político de los sectores juveniles del peronismo de izquierda en el penal de Rawson, escribió un recurso de amparo solicitándole a un juez federal que interviniese en favor de su traslado a un penal menos violento que el de la Unidad No 6. En ese escrito Kunkel, denunciaba las numerosas restricciones a las que los presos políticos estaban sometidos en este penal patagónico, y la total restricción de movimiento, pues no tenían permitido, ni siquiera durante el breve horario de recreo de una hora al día, realizar ejercicios físicos, "siendo pasible de sanción cualquier gesto al que se le atribuya ese carácter". ${ }^{18}$ Dicho reclamo revelaba, además, que los penitenciarios obligaban a los prisioneros a permanecer dentro de las celdas recostados en sus camastros 23 horas del día, provocando en brazos y piernas entumecimientos e inflamaciones.

Según ha relatado Joel G en sede judicial, detenido en Rawson desde mediados de 1977, en tal sentido, a los presos les suministraban comida por tan solo 450 calorías al día. ${ }^{19}$ Se trataba de una alimentación de raciones mínimas para que los internos no desfallecieran, pero a la vez, para obligar a los cuerpos a consumir al máximo de las reservas de energía y de grasa, quedando los detenidos sólo a piel y hueso. ${ }^{20} \mathrm{Un}$

18 Causa N. $^{\circ} \mathbf{5 0 0 / 8 0}$ sobre apremios y torturas en el Penal U6 de Rawson. Expediente N. ${ }^{\circ}$ $500 / 107 / 1980$. Sin fojas, ver carta inicial de Carlos K.al juez Omar Garzonio.

${ }^{19}$ Causa N. ${ }^{\circ} \mathbf{5 0 0 / 8 0}$ sobre apremios y torturas en el Penal U6 de Rawson. Ver fojas 1938 y ss.

${ }^{20}$ Es importante destacar que el reglamento prohibía el ingreso de todo tipo de alimentos enviados desde el exterior. De modo que los internos solo podían consumir unos pocos de una lista muy reducida de la proveeduría del penal que, por otro lado, se compraban, además, a precios poco convenientes con el dinero que depositaban los familiares en sus cuentas. 


\section{Los cuerpos como espacios de inscripción del poder: la experiencia de la prisión política en la Argentina durante los años sesenta y setenta}

tipo de manutención sumamente deficitaria que produjo en los prisioneros efectos a corto, mediano y largo plazo. Si primeramente esta insuficiencia redundó en una disminución notable del peso y de la masa muscular por la carencia de vitaminas, proteínas y minerales, en una fase posterior, derivó en agudos cuadros de desnutrición, trastornos hormonales, cuerpos fláccidos y en la caída del vello en distintas partes del cuerpo, afectando la fisonomía masculina.

Al encierro en celdas poco espaciosas, a la imposibilidad de realizar de ejercicio físico y a la débil alimentación, se le sumaron los maltratos físicos directos. Este es el caso, por ejemplo, de Carlos Samojedny, quien estuvo detenido 9 años en dicho penal, y relató que, entre febrero de 1975 y noviembre de 1980, fue sometido a doscientos treinta y cinco días de torturas, y dentro de este período, a sesenta días de torturas corporales sistemáticas. Samojedny ha explicado también, por ejemplo, que tanto de: "día y noche, en condiciones de desnudez, privación de alimentos, era sometido a continuos baños de agua fría, con el calabozo inundado, y golpeado con puños, porras, etc." (Samojedny, 1985: 15-16). En el testimonio que aportó a la Causa $\mathrm{N}^{\circ} 500 / 80$, este ex preso político, amplió el tema y señaló que, junto a ser conminados a ducharse con agua helada, si alguien intentaba realizar algún movimiento para evitar el shock de frío, era castigado aún más, obligándolo a permanecer bajo la ducha "porque si no éramos fuertemente golpeado".21 Samojedny declaró haber perdido 22 kilos de peso, y junto a ello, todos sus músculos, todos cambios muy drásticos que lo llevaron a sufrir además la merma transitoria del habla.

El proceso de desmasculinización se sirvió entonces de distintos modos de devastar físicamente a los prisioneros políticos, y este a la vez incluyó, la escasa, y en oportunidades nula, atención médica. De modo que, si los internos contaban con alguna afección, los médicos confeccionaban un diagnóstico a distancia pues no ingresaban en la celda para revisarlos. Algo que, según argumentaron los penitenciarios en las declaraciones judiciales, sucedía "por cuestiones de seguridad". Abdo Ekjabit, médico en el penal de Rawson, entre octubre de 1978 y hasta los primeros meses del año 1980, confirmó que a los problemas de salud que tenían los presos políticos se les daba en la mayoría de los casos, poca o nula significancia por el personal médico, sin que mediasen, sin embargo, órdenes escritas para tal cuestión. Lo que podría significar que los médicos no estaban obligados a no tomar contacto con el cuerpo enfermo de los prisioneros políticos, sin embargo, esto sucedía de forma sumamente excepcional. Y esas excepciones, por ejemplo, sobrevenían cuando el enfermo estaba internado en la enfermería o en el hospital del penal o cuando a través del diálogo, el médico intuía que podía estar sucediéndole algún síntoma de gravedad, y en ese caso, se pasaba al examen semiológico bajo la presencia de uno o dos celadores y de los enfermeros. ${ }^{22}$ Otros galenos, por su parte, avanzaban recentándoles a los prisioneros

\footnotetext{
${ }^{21}$ Causa N. $^{\circ} \mathbf{5 0 0 / 8 0}$ sobre apremios y torturas en el Penal U6 de Rawson. Ver fojas 444 y ss.

${ }^{22}$ Causa N. ${ }^{\circ} \mathbf{5 0 0 / 8 0}$ sobre apremios y torturas en el Penal U6 de Rawson. Ver fojas 4179 y ss.
} 


\section{Débora D'Antonio}

medicamentos inadecuados o en su defecto ponían en marcha internaciones compulsivas. Si los internos sufrían de cefaleas y de desequilibrios, producto, por ejemplo, de las pérdidas de la visión, que sucedían todo el tiempo, por la monotonía del "paisaje carcelario", se les recomendaba realizar ejercicios oculares con objetos que se encontrasen a mucha distancia, algo que evidentemente en las minúsculas celdas era imposible de practicar. De tal forma, el discurso y la práctica médica quedaban comprometidos con la idea de que el prisionero político era un "otro" al que no había que acercarse ni tocar. El mismo Dr. Ekjabit, indagado en los procesos judiciales por los maltratos llevados adelante por los carceleros en la zona de los calabozos de castigo del penal de Rawson, sostuvo que:

"Me atrevería a decir que con seguridad traería consecuencias nocivas para la salud de cualquier persona desde problemas musculares o articulares por la falta de movilización a problemas circulatorios por lo mismo, más la humedad o el frío, problemas bronquiales, etc., pero posiblemente donde una persona se siente más deteriorada es en el ámbito de lo psíquico". ${ }^{23}$

Los enfermos crónicos como los asmáticos o los cardíacos tenían prohibido guardar en sus celdas los medicamentos que les permitirían aligerar los efectos adversos de sus dolencias, lo que llevaba a que, en oportunidades, muchos de ellos se desequilibraran gravemente. Esta descompensación implicaba situaciones de estrés, gritos y tensiones, sobre todo cuando alguno de ellos alcanzaba un pico de crisis pulmonar o cardíaca. Un abuso de poder por parte de los médicos que colocaba al interno que necesitaba de su medicación, en una posición de extremo debilitamiento, donde para curarse debía someterse al capricho de su victimario. Los penitenciarios y los médicos se aprovecharon de esta situación y, haciendo un uso arbitrario de sus saberes y prerrogativas, obligaron a los internos a colocarse en situación de tutela, algo que atentaba, aunque estos tuviesen restringida su libertad de movimiento, contra lo que se esperaba socialmente de un varón. Portar la condición de varón en la sociedad en la que actuaban los presos políticos, remitía a la idea de conservación del autocontrol, de mantener la autoestima en alto, así como el estado de alerta y de competitividad frente a sus pares. Recordemos que a las mujeres se les atribuía el rol de locas, justamente porque experimentaban la politización y cuestionaban de hecho el valor racional y controlado "propio" de lo masculino, algo que producía incomodidades no solo entre los militares y penitenciarios sino también entre sus propios compañeros de militancia.

Hubo también políticas penitenciarias destructivas cuyos efectos se inscribieron en lo que tiene que ver con lo anímico. Lo importante para destacar en este punto, tal como se ha señalado para el caso del penal de Villa Devoto, es que la terapéutica implementada por la psiquiatría se centraba en la utilización de drogas con incidencia en el sistema nervioso central. Así, ciertas alteraciones comunes como lo

${ }^{23}$ Ídem. 


\section{Los cuerpos como espacios de inscripción del poder: la experiencia de la prisión política en la Argentina durante los años sesenta y setenta}

era el debilitamiento en la percepción producida por los prolongados encierros a oscuras; los cuadros depresivos; de ansiedad; de insomnio o las palpitaciones del corazón eran tratados casi exclusivamente con estos potentes medicamentos. Señala Carlos Samojedny al respecto que, la misión de uno de los médicos del penal, recordó en especial al Dr. Barck, se reducía a experimentar con preparados que alteraban la psiquis de los internos, especialmente con la droga de moda por esos años que llevaba el nombre comercial de Valium, un depresor del sistema nervioso central. Explicó este ex preso que "planchaban al interno o lo dormían como una seda (...) Al interno S. que era un depresivo, le daban un depresivo, en lugar de darle un antidepresivo, lo que lo aplastaba más y lo dormía y dormía". ${ }^{24}$

Con distintas técnicas, según los propios tiempos de los mecanismos represivos del Estado, los especialistas crearon una clasificación en el penal patagónico para aplicarles a los prisioneros un "tratamiento personalizado". De modo que al que tenía un cuadro psiquiátrico leve o a el que "lo fingía" se le podían sumar graves consecuencias si era tratado con medicamentos sedantes, y a los que una vez recetados estas pócimas se resistiesen abiertamente a su consumo podían obligarlos a ingerirlos. Las técnicas de desubjetivación promovían el uso copioso de drogas con el fin de quitar los estados de concentración y de atención en los presos y de aturdirlos, minando toda tipo de identificación positiva con otros varones y sin tener capacidad de reacción frente a los golpes. Si algún médico intentaba socorrer a los internos, los carceleros los amedrentaban con comentarios del tipo "a esta gente no hay que llevarle demasiado el apunte..." o "usted pierde demasiado tiempo atendiendo a los internos", reduciendo así cualquier posición más compasiva ${ }^{25}$. Por otro lado, a los internos que mostraban trastornos mentales severos se los trasladaba a la unidad $\mathrm{N}^{\circ} 20$ en la capital del país, específicamente al Hospital Municipal José Tiburcio Borda, uno de los centros de atención de salud mental más importante del país, rompiendo toda relación con sus compañeros de militancia, sostén fundamental, hasta ese momento, de las crisis anímicas.

Es así que en Rawson se recurrió fuertemente al saber de la medicina psiquiátrica y de la psicología e incluso, en oportunidades, a la sociología, con el fin de incidir en el proceso de desubjetivación. En tal sentido es interesante subrayar, que en una nota que remitieron los miembros del Comité Internacional de la Cruz Roja (CICR) al ministro del Interior, Albano Harguindeguy, luego de una visita de supervisión durante el año 1980, le solicitaban que el gobierno interviniese con premura para descomprimir la alarmante tensión psíquica que el servicio penitenciario provocaba entre los prisioneros políticos alojados en penal patagónico. ${ }^{26}$ En otra nota instaban directamente a las autoridades del penal a instrumentar el decreto № 780/79 en el

\footnotetext{
${ }^{24}$ Causa N. $^{\circ} \mathbf{5 0 0 / 8 0}$ sobre apremios y torturas en el Penal U6 de Rawson. Ver fojas 4424 y ss.

25 Causa N. $^{\circ} \mathbf{5 0 0 / 8 0}$ sobre apremios y torturas en el Penal U6 de Rawson. Ver fojas 4179 y ss.

${ }^{26}$ Nota del Comité Internacional de la Cruz Roja, Delegación Regional para América Latina Cono Sur, Buenos Aires, s/número con fecha del 14 de abril de 1980.
} 


\section{Débora D'Antonio}

que se proponía "contribuir a una disminución de la tensión psicológica". ${ }^{27}$ Este decreto, a pesar de que disponía de un carácter microscópico en la vigilancia de los presos, intentaba limitar ciertas acciones que el mismo servicio penitenciario evaluaba como arbitrariedades llevadas a cabo por su propio personal.

Debe señalarse además que por oposición a lo que se experimentó en el caso de las mujeres en la cárcel de Villa Devoto, el plan de desubjetivación y desmasculinización y la conversión en una víctima pasiva del varón preso político, no aparejó en consecuencia un plan de despaternalización. Una ausencia que pone en evidencia ciertos pactos patriarcales en las formas generizadas del ejercicio de la dominación ya que no era inteligible para el régimen militar hendir los lazos paternales a través de la laceración del vínculo paterno-filial.

\section{Conclusiones}

En este artículo se examinaron cómo se inscribió y encontró su forma específica en el servicio penitenciario la Doctrina de Seguridad Nacional. Las cárceles que albergaron a personas prisioneras políticas ensayaron durante las décadas del sesenta y setenta, particulares estrategias de desubjetivación. Cuando todas las acciones fueron objeto de escrutinio y los dispositivos represivos tuvieron una certera unidad en torno al control de la lucha "subversiva", el discurso oficial de las elites penitenciarias y militares encontró en las pautas de género una forma corrosiva de dominación que impactó en las técnicas de atomización y de vigilancia. Así, por ejemplo, entre las prisioneras se intentó debilitar el ejercicio de la maternidad, y en consecuencia erosionar el vínculo que podían establecer con sus hijos e hijas. Y también, mientras se les remarcó su culpabilidad por haber abandonado los roles de género establecidos socialmente, se las acusó de locas con el fin de desprestigiar y despolitizar sus planteos en sus propios términos.

Las declaraciones de los ex presos políticos del penal de Rawson que integran la voluminosa causa $\mathrm{N} .^{\circ} 500 / 80$, en la que además dieron su testimonio médicos, enfermeros, carceleros, directores del penal y otras diversas figuras militares implicadas en los circuitos represivos, muestran la existencia de una institución represiva enmarcada en prácticas que, mientras contaban con dinámicas regulares y consuetudinarias, a la vez desarrollaban prácticas propias de los años de clandestinización de la faz más represiva. Unas y otras, no obstante, se articularon para apuntalar y minar la subjetividad política de la mano del ataque al cuerpo físico y psíquico de los prisioneros. Es lo burocrático, por su parte, lo que exigía su materialización en registros, memos, certificaciones, historias clínicas o fichas. Estos documentos producidos en el transcurso de la actividad regular de esta institución dejaron al descubierto los abusos, las iniquidades y las injusticias. A la vez permiten entrever que el sistema penitenciario fue totalmente imprevisible en sus decisiones

\footnotetext{
${ }^{27}$ Nota del Comité Internacional de la Cruz Roja, Delegación Regional para América Latina Cono Sur, Buenos Aires, N. ${ }^{\circ} 104$ con fecha del 18 de abril de 1980.
} 
ya que podía curar mientras apuntaba en detalle las huellas de un cuerpo torturado, hacer (y hacía) caso omiso de los maltratos de su personal mientras atendía con absoluta indolencia e impericia el sufrimiento de las y los prisioneros. De modo que la institución no siempre reaccionaba de la misma manera. Mientras se proponía aliviar el dolor, al mismo tiempo, esto pasaba a ser una prerrogativa propiamente penitenciaria que ponía de manifiesto centralmente la desigualdad del poder: la máxima de sanar o de dejar morir. Dadores de vida y dadores de muerte es la expresión que ha utilizado Pilar Calveiro en su análisis sobre el poder de los desaparecedores en los centros clandestinos de detención respecto de los militares y de su pretensión de convertirse en dioses (Calveiro, 2004). En las cárceles no se alcanzó esa potencia, pero, no obstante, estas prácticas dejaron entrever los vasos comunicantes con las lógicas, los dispositivos y los mecanismos represivos.

Si bien no ha sido objeto de análisis de este texto, vale la pena señalar que el aprendizaje del proceso de prisionización llevó a que las personas presas por razones políticas comprendieran que la mejor forma para desarmar las estrategias de desubjetivación requería de una organización colectiva. En tal sentido, las vivencias de la lucha política, las experiencias carcelarias previas y, sobre todo, las representaciones que estas personas manejaban sobre cómo debían transitarse los tiempos en el encierro, les permitió sostenerse individual y colectivamente. Si bien la unidad no fue fácil entre las prisioneras y los prisioneros con formaciones y perspectivas diferentes, el alto nivel de politización que acarreaban les permitió, no obstante, construir lazos solidarios para mantenerse a distancia de las formas de sojuzgamiento y humillación penitenciarias. Estos lazos, por otro lado, se prolongaron posteriormente en la socialización que experimentaron luego de que alcanzaran la libertad.

\section{Referencias bibliográficas}

Bergalli, R. (1972). Nuevo régimen carcelario para detenidos de máxima peligrosidad". Nuevo Pensamiento Penal 1 (3), 471-475.

Boccanera, J. (2006). El testimonio de ex presas políticas de Villa Devoto en el libro Nosotras. Presas políticas. http://www.redroom.com/author/alicia-kozameh/bi

Calveiro, P. (2004). Poder y desaparición en los campos de concentración en Argentina. Buenos Aires: Colihue.

D’Antonio, D. (2016). La prisión en los años setenta: Historia, género y política, (autora). Buenos Aires: Editorial Biblos.

Eidelman, A. (2010). El buque-cárcel Granadero y los presos políticos, 1972-1973. VI Jornadas de Sociología de la UNLP. Universidad Nacional de La Plata. Facultad de 


\section{Débora D'Antonio}

Humanidades y Ciencias de la Educación. Departamento de Sociología, La Plata.

Marcó del Pont, L. (1982). Penología y sistemas carcelarios. Tomo I, Penología. Buenos Aires: Luis De Palma.

Merenson, S. (2004) Y hasta la muerte en tus labios... memorias de las ex presas políticas del penal de Villa Devoto en el trascurso de la última dictadura militar en la argentina, Tesis Maestría, IDES, IDAES, UNSAM.

Rojas, P. (1996). La tortura: causas, efectos y tratamientos, en: Persona, Estado, poder: estudios sobre salud mental, vol. 2. 1990-1995. Santiago: CODEPU, 75-87.

Sapriza, G. (2009) "Memorias de mujeres en el relato de la dictadura" (Uruguay 1973-1985), en Deportate, Esuli, Profughe, Rivista Telematica di studi sulla memoria femminnile, $\quad \mathrm{N} .^{\circ} \quad 11 . \quad$ Universitá Ca FoscariVenezia, https://www.unive.it/media/allegato/dep/n 1speciale/05 Sapriza.pdf

Samojedny, C. (1986) Psicología y dialéctica del represor y reprimido: experiencias de la unidad carcelaria 6, Rawson. Buenos Aires: Rojoblanco.

\section{Documentos consultados}

Causa N. ${ }^{\circ} 500 / 80$ sobre apremios y torturas en el Penal U6 de Rawson (1980) obrante en Archivo Nacional de la Memoria

Decreto ley N. ${ }^{\circ} 412$ (1958).

Documentación del Comité Internacional de la Cruz Roja, Delegación Regional para América Latina Cono Sur, Buenos Aires, obrante en Archivo Nacional de la Memoria (1980).

Foro de Buenos Aires por la Vigencia de los Derechos Humanos (1973).

Ley del “Reglamento de Detenidos de Máxima Peligrosidad” N. o 19.863 (1972)

Ley Penitenciaria Nacional N. o 14.467 (1958).

Ley N. ํ 19.594 (1972)

Historias clínicas del Hospital Penitenciario de Villa Devoto obrantes en Archivo Nacional de la Memoria.

Libros de novedades obrantes en Archivo Nacional de la Memoria. 
Los cuerpos como espacios de inscripción del poder: la experiencia de la prisión política en la Argentina durante los años sesenta y setenta

Recibido: $15 / 09 / 2019$

Evaluado: $10 / 10 / 2019$

Versión Final: 07/11/2019 